\title{
Performance Analysis of Electrochemical Micro Machining of Titanium (Ti-6Al-4V) Alloy under Different Electrolytes Concentrations
}

\author{
Geethapriyan Thangamani ${ }^{1}$, Muthuramalingam Thangaraj ${ }^{2, *} \mathbb{C}$, Khaja Moiduddin ${ }^{3, *} \mathbb{C}$, Syed Hammad Mian ${ }^{3}(\mathbb{D}$, \\ Hisham Alkhalefah ${ }^{3}$ (D) and Usama Umer ${ }^{3}$ (D)
}

1 Department of Mechanical Engineering, SRM Institute of Science and Technology, SRM Nagar, Kattankulathur 603203, Kanchipuram, Chennai, TN, India; geethapt@srmist.edu.in

2 Department of Mechatronics Engineering, SRM Institute of Science and Technology, SRM Nagar, Kattankulathur 603203, Kanchipuram, Chennai, TN, India

3 Advanced Manufacturing Institute, King Saud University, Riyadh 11421, Saudi Arabia; smien@ksu.edu.sa (S.H.M.); halkhalefah@ksu.edu.sa (H.A.); uumer@ksu.edu.sa (U.U.)

* Correspondence: muthurat@srmist.edu.in (M.T.); khussain1@ksu.edu.sa (K.M.); Tel.: +91-9994872013 (M.T.); +966-540542861 (K.M.)

Citation: Thangamani, G.;

Thangaraj, M.; Moiduddin, K.;

Mian, S.H.; Alkhalefah, H.; Umer, U.

Performance Analysis of

Electrochemical Micro Machining of Titanium (Ti-6Al-4V) Alloy under Different Electrolytes Concentrations. Metals 2021, 11, 247. https://doi.org/ $10.3390 /$ met11020247

Academic Editor: Artur Shugurov

Received: 30 December 2020

Accepted: 29 January 2021

Published: 2 February 2021

Publisher's Note: MDPI stays neutral with regard to jurisdictional claims in published maps and institutional affiliations.

Copyright: (c) 2021 by the authors. Licensee MDPI, Basel, Switzerland. This article is an open access article distributed under the terms and conditions of the Creative Commons Attribution (CC BY) license (https:/ / creativecommons.org/licenses/by/ $4.0 /)$.

\begin{abstract}
Titanium alloy is widely used in modern automobile industries due to its higher strength with corrosion resistance. Such higher strength materials can be effectively machined using unconventional machining processes, especially the electro-chemical micro machining (ECMM) process. It is important to enhance the machining process by investigating the effects of electrolytes and process parameters in ECMM. The presented work describes the influence of three different combinations of Sodium Chloride-based electrolytes on machining Titanium (Ti-6Al-4V) alloy. Based on the ECMM process parameters such as applied voltage, electrolytic concentration, frequency and duty cycle on response, characteristics are determined by the Taguchi design of experiments. The highest material removal rate (MRR) was achieved by the Sodium Chloride and Sodium Nitrate electrolyte. The combination of Sodium Chloride and Citric Acid achieve highest Overcut and Circularity. The optimal overcut was observed from the Sodium Chloride and Glycerol electrolyte due to the presence of glycerol. The better conicity was obtained from Sodium Chloride and Citric Acid in comparison with other electrolytes. A Sodium Chloride and Glycerol combination could generate better machined surface owing to the chelating effect of Glycerol.
\end{abstract}

Keywords: titanium alloy; electrolyte; ECMM; sodium chloride; glycerol

\section{Introduction}

Titanium (Ti-6Al-4V) alloy is used widely in automobile, aerospace, power sectors and the pharmaceutical industry due to its property of resistance towards corrosion in the wide range of applications [1]. Nowadays, as the demand of micro components has grown in the industry, electro-chemical micro machining (ECMM) is appearing as a promising technique to machine these miniature components with exceptional precision. In the process, the dissolution of the workpiece takes place on the application of voltage between the anode and cathode according to the electrolysis laws given by Michael Faraday. The reaction products precipitated during the electrolysis process are separated from the electrode gap by a fast-flowing electrolyte [2]. ECMM and electrical discharge micro machining (EDMM) have many advantages such as accuracy of the machined components, higher rate of machining, featureless finish and absence of wear on the tools [3]. The processes also aid in machining three-dimensional microstructures. The ECM process includes corrosion products despite not being defined exclusively as a corrosion process owing to anodic dissolution although mostly driven by redox [4,5]. 
The process of ECMM is immensely affected by the choice of electrolyte, which is used to perform the corrosion process [6]. Sen and Shan (2005) presented the electrochemical machining process for drilling of macro to micro holes with accurate surface and for the application in the computer, electronic, micro-mechanics and aerospace industries. This paper represents the new developments and recent trends for machining micro-level quality holes in difficult-to-machine materials [7]. Rajurkar et al. (1998) discussed the improvement of accuracy by the reduction of sludge using passive electrolytes. The waste generation from the machining surface has minimum machining allowance to increased localization effect for improving performance of the ECMM process. The passive electrolytes like $\mathrm{NaNO}_{3}$ have been used to achieve better machining characteristics such as higher unit removal and machining exactness [8]. Sodium chlorate $\left(\mathrm{NaClO}_{3}\right)$, sodium chloride $(\mathrm{NaCl})$ and sodium nitrate $\left(\mathrm{NaNO}_{3}\right)$ are frequently used electrolytes in the process owing to their ability to form a significant quantity of sludge as the reactional by-product, which creates issues like clogging [9]. A significant amount of research has already been performed focusing on the use of different types of electrolytes in the ECMM process. It was suggested that high accuracy for machined component and low quantity of sludge can be achieved by the use of electrolytes of lower concentration [10]. Ayappan et al. found that oxygenated aqueous $\mathrm{NaCl}$ provides better surface finish than aqueous $\mathrm{NaCl}$ in the machining of alloy steel specimen [11]. Tang et al. used various compositions of $\mathrm{NaNO}_{3}$ and $\mathrm{NaClO}_{3}$ to machine a special stainless-steel workpiece to study the various response characteristics [12]. Kirchner et al. used $\mathrm{HF}$ and $\mathrm{HCl}$ to generate 3D microstructures on the stainless-steel specimen [13]. Huaiqian et al. investigated the utilization of pure water as an electrolyte to generate holes and cavities on a stainless steel plate [14]. Naoki Shibuya et al. has fabricated micro pins using $\mathrm{NaNO}_{3}$ as an electrolyte [15]. It was evident from the aforementioned research that response characteristics in the ECMM process are immensely affected by the type and concentration of electrolytes. Spieser and Ivanov (2013) discussed the recent developments and issues in the ECM process to maintain a narrow gap between the tool electrode and workpiece during the machining process to obtain accuracy. The smaller value of IEG is used to control the micro-spark generation in the machining surface. It was stated that the overall machining efficiency has been mainly influenced by input process parameters. The stress-free micro-hole has been produced with complex shapes for automobile and aerospace applications [16]. Rajurkar et al. (1999) described that an endeavor has been made to develop an ECMM process for carrying out innovative research to control the ECMM process parameters to get better machining accuracy. The developments of the ECMM process are in the field of design of the tool, pulse period for current, micro-size shaping, surface finishing, numerically controlled ECM, ECM environmental concerns, hybrid process and industrial application for various industries [17]. Kozak and Rajurkar (2004) included the study of pulse electrochemical micro machining process for stress-, burr- and crack-free micro components on the machining surface. The influence of process parameters such as applied voltage and feed rate on performance measures has been studied. The reduction of inter-electrode gap is used to increase localized dissolution for improved accuracy in the ECMM process [18,19]. The surface quality of the metal implants such as titanium alloy specimens in the medical field should be better as much as possible $[20,21]$. It can be made possible by enhancement of the electrochemical micro machining process.

From the referred literature, it has been understood that very little attention has been given to analyze the influence of electrolytes on quality measures using the ECMM process. Many research works are available that analyze the effect of electrolyte concentrations. Nevertheless, only few works are available that investigate the influence of electrolytes in different proportions along with the process parameters on machining titanium alloy specimens in the ECMM process [22]. Hence, the present investigation was carried out. The objective of the study is to examine the influence of a combination of different electrolytes like Sodium Chloride $(\mathrm{NaCl})+$ Sodium Nitrate $\left(\mathrm{NaNO}_{3}\right)$, Sodium Chloride $(\mathrm{NaCl})+$ Glycerol $\left(\mathrm{C}_{3} \mathrm{H}_{8} \mathrm{O}_{3}\right)$ and Sodium Chloride $(\mathrm{NaCl})+$ Citric Acid $\left(\mathrm{C}_{6} \mathrm{H}_{8} \mathrm{O}_{7}\right)$ in the 
ECMM process on machining Titanium (Ti-6Al-4V) alloy using copper tool electrode. Various output parameters such as MRR, overcut, conicity and circularity are measured by varying the input parameters such as applied voltage, electrolyte concentration, frequency and duty cycle. The micro structural analysis was carried out to understand the variation of grains around the machined area of each specimen.

\section{Materials and Methods}

The ECMM setup (Sinergy nano system, Navi Mumbai, India) consists of a power input, control unit to set the process parameters, electrolyte supply system and a machining chamber which contains the tool and the workpiece along with the electrolyte, as shown in Figure 1 [23]. Titanium (Ti-6Al-4V) alloy with the size of $(50 \mathrm{~mm} \times 50 \mathrm{~mm} \times 3 \mathrm{~mm}$ ) was chosen as the workpiece due to its importance in manufacturing industries.

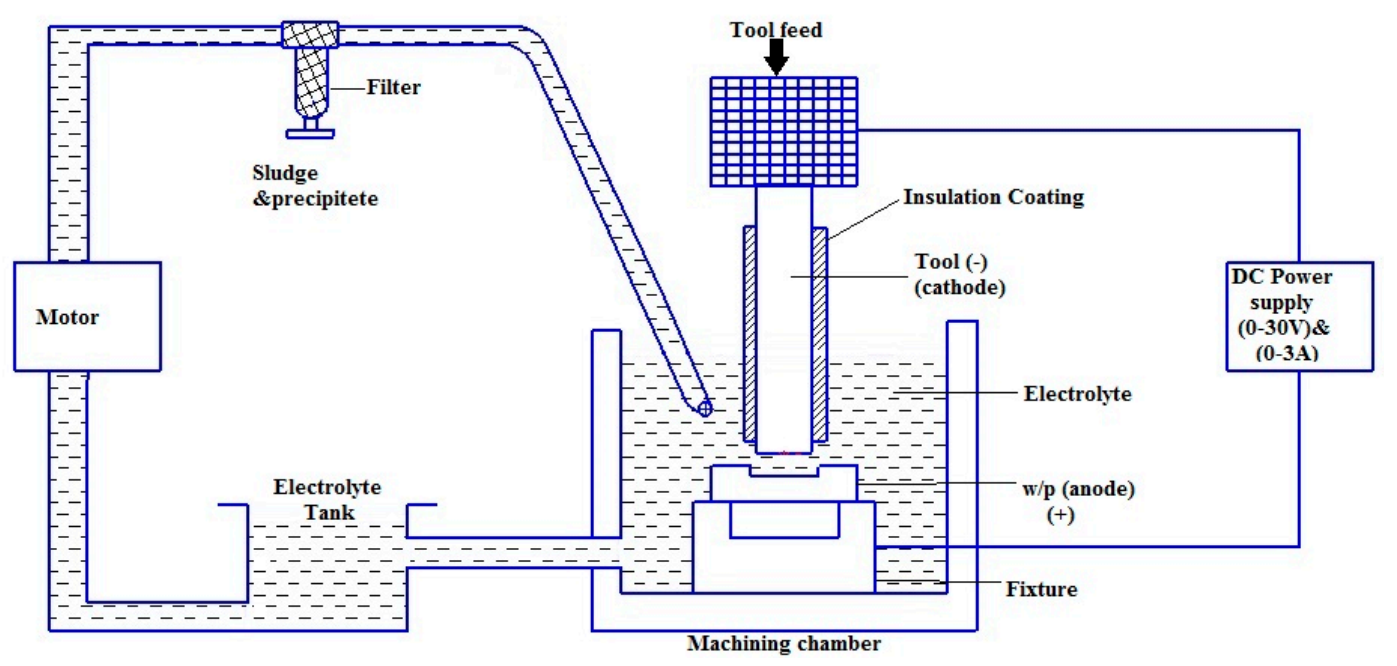

Figure 1. Schematic representation of the electro-chemical micro machining (ECMM) process.

The workpiece is fixed using the plastic clamps to avoid the imbalanced surface calibration and the acrylic tank is sealed to avoid the leakage of electrolytes. The cathode is brought to the closest non-contact distance possible near the anode manually by using the screw mechanism. The ECMM process is started after introducing the electrolyte in the machining chamber such that the space between the tool and workpiece is well immersed. The ECMM process is performed by the sinking of the tool, forming its replica. In the present study, the machining experiments were performed with different combinations of Sodium Chloride $(\mathrm{NaCl})+$ Sodium Nitrate $\left(\mathrm{NaNO}_{3}\right)$, Sodium Chloride $(\mathrm{NaCl})+$ Glycerol $\left(\mathrm{C}_{3} \mathrm{H}_{8} \mathrm{O}_{3}\right)$ and Sodium Chloride $(\mathrm{NaCl})+$ Citric Acid $\left(\mathrm{C}_{6} \mathrm{H}_{8} \mathrm{O}_{7}\right)$ (Anmol Chemicals, Mumbai, India) under Taguchi-based $\mathrm{L}_{18}$ orthogonal array $(\mathrm{OA})$ as shown in Table 1 [22]. The Copper tool electrode was used as a tool electrode with diameter of $0.1 \mathrm{~mm}$. The performance measures such as metal removal rate (MRR), overcut $(\mathrm{OC})$, conicity $(\mathrm{CN})$ and circularity (CY) were considered as response parameters in the present study. MRR was calculated as weight loss of workpiece specimens that happened during machining time. The values of $\mathrm{OC}, \mathrm{CN}$ and $\mathrm{CY}$ were computed with the help of an Optic Light Vision Measurement System (SIPCON, Chennai, India) and digital micrometer (Mitutoyo, Osaka, Japan) [23]. The cut region image was acquired using a more accurate Vision measuring system. The overcut was directly computed from the image using a calibrated scale measurement technique. The scanning electron microscope-based images (Hitachi, Tokyo, Japan) were utilized to analyze the topography of the machined workpiece surface. The process parameter combinations based on Design of Experiments are shown in Table 2. As per the Taguchi Design of Experiments approach, $\mathrm{L}_{18}$ orthogonal array $(\mathrm{OA})$ has been chosen since the present study does contain five process factors with three levels [24]. 
Table 1. Selection of process variables with their levels.

\begin{tabular}{|c|c|c|c|c|c|c|c|c|c|c|}
\hline \multirow{2}{*}{$\begin{array}{c}\text { Combination } \\
\text { Process Parameter }\end{array}$} & \multirow{2}{*}{ Symbol } & \multicolumn{3}{|c|}{$\mathrm{NaCl}+\mathrm{NaNO}_{3}$} & \multicolumn{3}{|c|}{$\mathrm{NaCl}+\mathrm{C}_{3} \mathrm{H}_{8} \mathrm{O}_{3}$} & \multicolumn{3}{|c|}{$\mathrm{NaCl}+\mathrm{C}_{6} \mathrm{H}_{8} \mathrm{O}_{7}$} \\
\hline & & $\mathbf{I}$ & II & III & I & II & III & $\mathbf{I}$ & II & III \\
\hline Applied voltage(V) & $\mathrm{V}$ & 10 & 12 & 14 & 10 & 12 & 14 & 10 & 12 & 14 \\
\hline Electrolyte Concentration $(\mathrm{g} / \mathrm{L})$ & $\mathrm{EC}$ & $10+7$ & $10+9$ & $10+3$ & $10+4$ & $10+7$ & $10+8$ & $10+16$ & $10+5$ & $10+3$ \\
\hline Micro-tool feed rate $(\mu \mathrm{m} / \mathrm{s})$ & MF & 0.1 & 0.5 & 1 & 0.1 & 0.5 & 1 & 0.1 & 0.5 & 1 \\
\hline Frequency (Hz) & $\mathrm{F}$ & 50 & 60 & 70 & 50 & 60 & 70 & 50 & 60 & 70 \\
\hline Duty Cycle (\%) & DC & 33 & 50 & 66 & 33 & 50 & 66 & 33 & 50 & 66 \\
\hline
\end{tabular}

Table 2. Experimental methodology of the present study.

\begin{tabular}{|c|c|c|c|c|c|c|c|}
\hline \multirow{2}{*}{ S. No } & \multirow{2}{*}{$\mathbf{V}$} & \multicolumn{3}{|c|}{ EC } & \multirow{2}{*}{ MF } & \multirow{2}{*}{$\mathbf{F}$} & \multirow{2}{*}{ DC } \\
\hline & & $\mathrm{NaCl}+\mathrm{NaNO}_{3}$ & $\mathrm{NaCl}+\mathrm{C}_{3} \mathrm{H}_{8} \mathrm{O}_{3}$ & $\mathrm{NaCl}+\mathrm{C}_{6} \mathrm{H}_{8} \mathrm{O}_{7}$ & & & \\
\hline 1 & 10 & 17 & 14 & 26 & 0.1 & 50 & 33 \\
\hline 2 & 10 & 19 & 17 & 15 & 0.5 & 60 & 50 \\
\hline 3 & 10 & 13 & 18 & 13 & 1 & 70 & 66 \\
\hline 4 & 12 & 17 & 14 & 26 & 0.1 & 60 & 50 \\
\hline 5 & 12 & 19 & 17 & 15 & 0.5 & 70 & 66 \\
\hline 6 & 12 & 13 & 18 & 13 & 1 & 50 & 33 \\
\hline 7 & 14 & 17 & 14 & 26 & 0.5 & 50 & 66 \\
\hline 8 & 14 & 19 & 17 & 15 & 1 & 60 & 33 \\
\hline 9 & 14 & 13 & 18 & 13 & 0.1 & 70 & 50 \\
\hline 10 & 10 & 17 & 14 & 26 & 1 & 70 & 50 \\
\hline 11 & 10 & 19 & 17 & 15 & 0.1 & 50 & 66 \\
\hline 12 & 10 & 13 & 18 & 13 & 0.5 & 60 & 33 \\
\hline 13 & 12 & 17 & 14 & 26 & 0.5 & 70 & 33 \\
\hline 14 & 12 & 19 & 17 & 15 & 1 & 50 & 50 \\
\hline 15 & 12 & 13 & 18 & 13 & 0.1 & 60 & 66 \\
\hline 16 & 14 & 17 & 14 & 26 & 1 & 60 & 66 \\
\hline 17 & 14 & 19 & 17 & 15 & 0.1 & 70 & 33 \\
\hline 18 & 14 & 13 & 18 & 13 & 0.5 & 50 & 50 \\
\hline
\end{tabular}

\section{Results and Discussion}

The Titanium (Ti-6Al-4V) alloy specimens have been machined using ECMM process. In this section, the effect of process parameters and influence of various electrolytes on response parameters such as MRR, overcut, conicity and circularity are discussed. Figure 2 demonstrates the impact of different combinations of electrolytes on different quality measures in the ECMM process.

\subsection{Effect of Electrolytes Andprocess Parameters on MRR}

It can be inferred from the experimental data obtained that electrolyte concentration was the strongest influencing factor on $\mathrm{MRR}$ for the combination of $\mathrm{NaCl}+\mathrm{NaNO}_{3}$ and $\mathrm{NaCl}+\mathrm{C}_{3} \mathrm{H}_{8} \mathrm{O}_{3}$. The higher electrolyte concentration increases conductivity, which in turn increases the stray current, which results in a decrease of localization, consequently decreasing the MRR [25]. When machining is carried out with the second combination of electrolytes, glycerol acts as a chelating agent, which increases bonding of suspended ions resulting in an increase of current density and subsequently the volume of material removed. Applied voltage appeared as the most contributing parameter on MRR for the combination of $\mathrm{NaCl}+\mathrm{C}_{6} \mathrm{H}_{8} \mathrm{O}_{7}$. On application of a high voltage, the stray current reduces, which results in the increases of localization, thus increasing the MRR [26]. The main material removal mechanism in the electro-chemical machining process is the anodic dissolution. Sodium ions are considered as the aggressive anions in electro-chemical micro machining process, which induce more liberation of the anodic particles from the machining surface. This has resulted in higher material removal rate in the ECM process. It was evident from the Figure 3 that $\mathrm{NaCl}+\mathrm{NaNO}_{3}$ has generated better MRR than the other 
two combinations of electrolytes due to the presence of more Sodium $(\mathrm{Na}+)$ ions, which are easily displaced by elements of titanium alloy according to the reactivity series. From the experimental data obtained, it is seen that the first electrolyte combination has generated $56 \%$ and $24 \%$ higher MRR than $\mathrm{NaCl}+\mathrm{C}_{3} \mathrm{H}_{8} \mathrm{O}_{3}$ and $\mathrm{NaCl}+\mathrm{C}_{6} \mathrm{H}_{8} \mathrm{O}_{7}$, respectively [27].

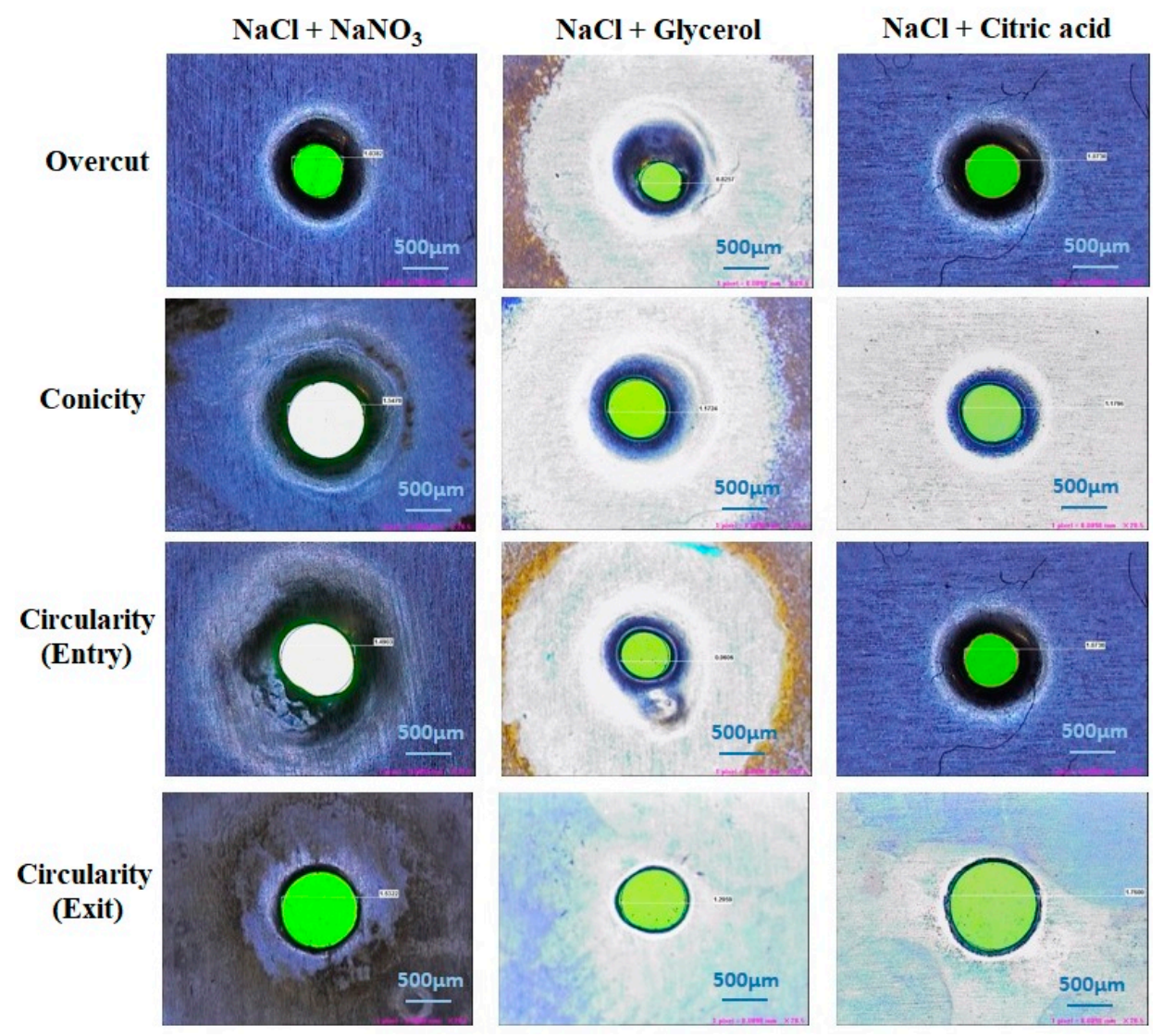

Figure 2. Effects of different electrolyte combinations on quality measures.

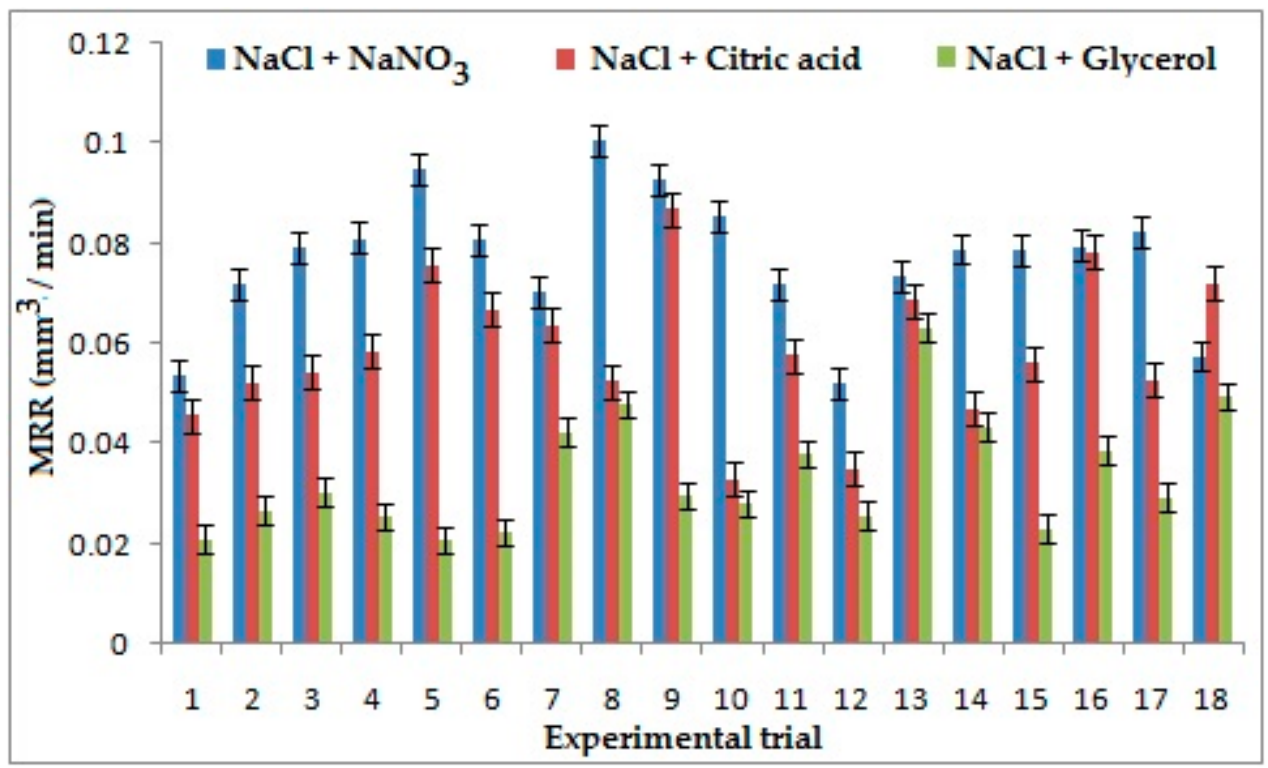

Figure 3. Effects of Electrolytes and process parameters on metal removal rate (MRR). 


\subsection{Effect of Electrolytes Andprocess Parameters on Overcut}

Applied voltage appeared as the strongest influencing parameter on overcut as shown in Figure 4 for the combination of $\mathrm{NaCl}+\mathrm{NaNO}_{3}$, because on the application of high voltage, stray current decreases and side current decreases which results in the reduction of overcut. For the combination of $\mathrm{NaCl}+\mathrm{C}_{3} \mathrm{H}_{8} \mathrm{O}_{3}$, the frequency was found as the strongest contributing factor as it depends upon the duration of pulse $\mathrm{ON}$ and pulse OFF time. With an increase of frequency, the pulse duration decreases and duty cycle ratio increases, which shows that high pulse ON time will result in increased current supply, which in turn decreases the localization, increasing the stray current, resulting in high overcut. Electrolyte concentration appeared as the strongest influencing factor for the combination of $\mathrm{NaCl}+\mathrm{C}_{6} \mathrm{H}_{8} \mathrm{O}_{7}$ because higher electrolyte concentration leads to a generation of a larger number of ions during the ECMM process, which leads to larger ionization and decreases the stray current causing a reduction in overcut $[28,29]$. The low value of overcut is considered better in machining. It is apparent from Figure 4 that the combination of $\mathrm{NaCl}+\mathrm{C}_{3} \mathrm{H}_{8} \mathrm{O}_{3}$ yields better overcut than the other two combinations of the electrolyte. It is evident from the experimental data that it produces $40 \%$ and $22 \%$ improvement in overcut than the combination of $\mathrm{NaCl}+\mathrm{NaNO}_{3}$ and $\mathrm{NaCl}+\mathrm{C}_{6} \mathrm{H}_{8} \mathrm{O}_{7}$ because of the chelating effect of Glycerol, which influences greater bonding of ions and thereby reduces the stray current during machining, resulting in lesser overcut [30]. During the machining, chromium chloride and chromium hydroxide get removed as sludge.

$$
\begin{gathered}
\text { At Anode }: \mathrm{Cr} \rightarrow \mathrm{Cr}^{6+}+6 \mathrm{e}^{-} \\
\text {Sludge Reaction : } \mathrm{Cr}^{6+}+6 \mathrm{Cl} \rightarrow \mathrm{Cr}(\mathrm{Cl})_{6} \\
\mathrm{Cr}^{6+}+6(\mathrm{OH}) \rightarrow 6 \mathrm{Cr}(\mathrm{OH})_{6} \\
\mathrm{CrCl}_{2}+2 \mathrm{OH} \rightarrow \mathrm{Cr}(\mathrm{OH})_{2}+2 \mathrm{Cl}
\end{gathered}
$$

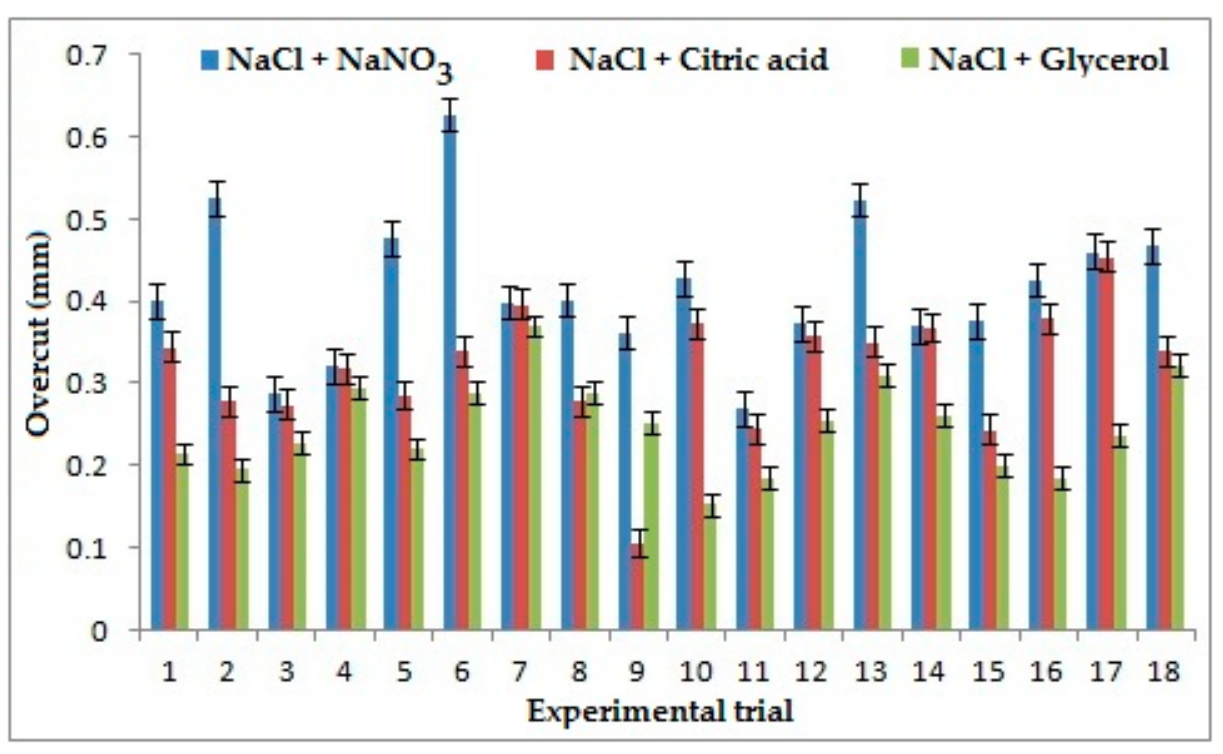

Figure 4. Effects of electrolytes and process parameters on overcut.

\subsection{Effect of Electrolytes Andprocess Parameters on Conicity}

The strongest influencing factor on conicity for the combination of $\mathrm{NaCl}+\mathrm{NaNO}_{3}$ is duty cycle, because with the increment of pulse ON time $\left(\mathrm{T}_{\mathrm{on}}\right)$ the flow of current between the electrode and workpiece increases. When $\mathrm{T}_{\text {on }}$ is lower than $\mathrm{T}_{\text {off }}$ the machining time is less, which increases flush around the machining area and results in better conicity. However, for the combination of $\mathrm{NaCl}+\mathrm{C}_{3} \mathrm{H}_{8} \mathrm{O}_{3}$ frequency appears as the strongest contributing parameter. It was seen that conicity rises with increases in frequency, which 
results in the reduction of pulse duration, which resulted in higher $\mathrm{T}_{\text {on }}$. This could result in higher conicity of the ECMM process. Electrolyte concentration was observed as the strongest influencing parameter for the combination of $\mathrm{NaCl}+\mathrm{C}_{6} \mathrm{H}_{8} \mathrm{O}_{7}$ because ionization rate reduces with a decrease in concentration of electrolytes, which results in the increases of stray current, thus generating high conicity [29]. The lower value of conicity was considered better in machining. It was evident from Figure 5 that the combination of $\mathrm{NaCl}+\mathrm{C}_{6} \mathrm{H}_{8} \mathrm{O}_{7}$ produced better conicity than the other two combinations. It was observed that the conicity could be improved by $70 \%$ and $39 \%$ in comparison to the combination of $\mathrm{NaCl}+\mathrm{NaNO}_{3}$ and $\mathrm{NaCl}+\mathrm{C}_{3} \mathrm{H}_{8} \mathrm{O}_{3}$. The presence of $\mathrm{NaCl}$ causes ionization in solution and citric acid reduces smutting around the machined hole with less sludge formation which results in a well-defined profile with less conicity [28].

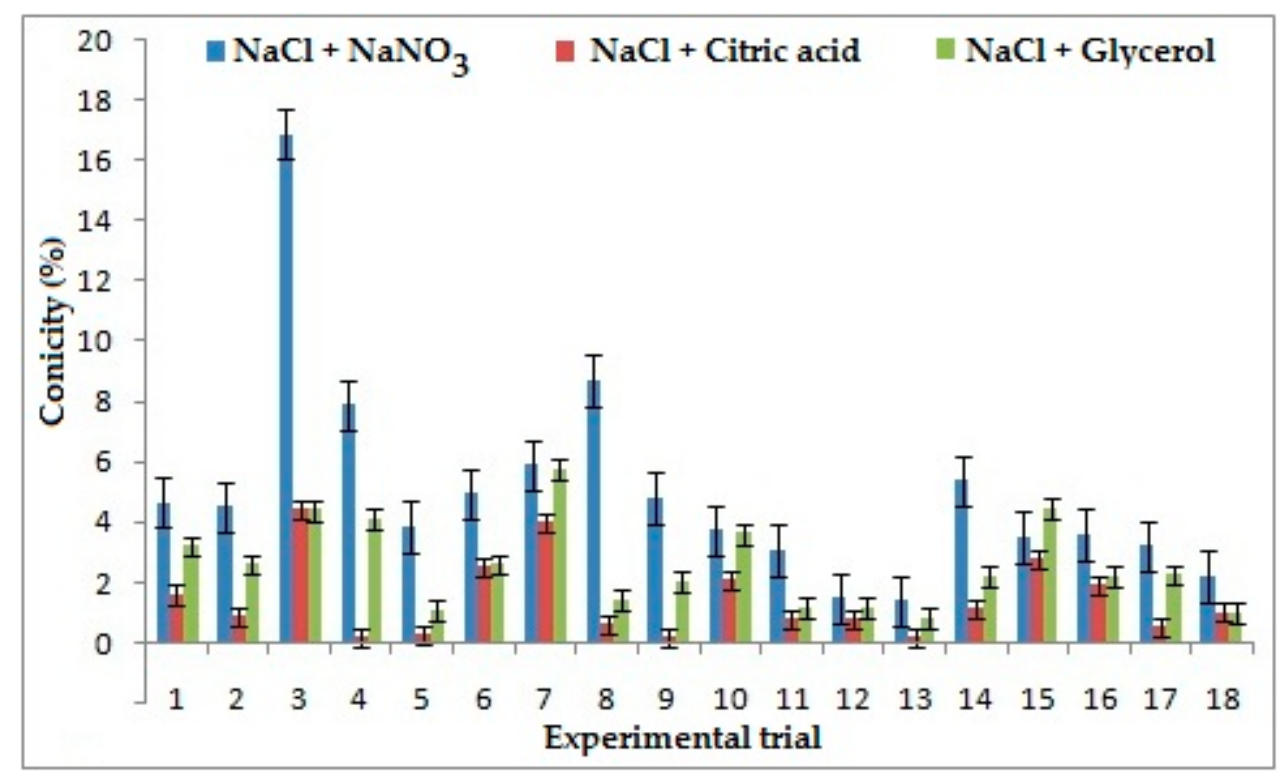

Figure 5. Effects of electrolytes and process parameters on conicity.

\subsection{Effect of Electrolytes and Process Parameters on Circularity at Entry and Exit}

During the tool entry, frequency was considered as the most influential parameter on circularity for the combination of $\mathrm{NaCl}+\mathrm{NaNO}_{3}$ as shown in Figure 6, because as frequency increases it results in an increase of pulse $\mathrm{ON}$ time, which in turn increases the duration of current passed, which consequently reduces localization and increases circularity. However, for the combination of $\mathrm{NaCl}+\mathrm{C}_{3} \mathrm{H}_{8} \mathrm{O}_{3}$ duty cycle is observed as the most influential parameter because as the pulse $\mathrm{ON}$ time increases the current flow between the electrode and work piece increases. It leads to a higher dissolution of ions which results in a decrease of flush time that helps remove the sludge formed around the machining area. Frequency is found as the most influential parameter for $\mathrm{NaCl}+\mathrm{C}_{6} \mathrm{H}_{8} \mathrm{O}_{7}$ as low frequency decreases the pulse $\mathrm{ON}$ time, which reduces the duration of machining between each pulse cycle and increases flushing and formation of sludge on the surface, thereby giving better machining and reducing circularity. However, for the tool exit, applied Voltage is considered as the most influential parameter for all three combinations of electrolytes because high voltage helps in dissolution of ions which increases the stray current and reduces the localization, resulting in increase of circularity.

A low value of Circularity is considered better in machining processes. It was inferred that $\mathrm{NaCl}+\mathrm{NaNO}_{3}$ has improved the circularity at entry by $62 \%$ when compared to other combinations of electrolytes. The dissolution rate of $\mathrm{NaCl}+\mathrm{NaNO}_{3}$ in the solvent is lesser, which reduces the stray current on the surface, thereby machining a proper through hole resulting in less circularity. However, the best circularity at exit is presented by $\mathrm{NaCl}+$ $\mathrm{NaNO}_{3}$ as shown in Figure 7. It reduces the circularity by $76 \%$ and $79 \%$ comparatively to the combination of $\mathrm{NaCl}+\mathrm{C}_{6} \mathrm{H}_{8} \mathrm{O}_{7}$ and $\mathrm{NaCl}+\mathrm{C}_{3} \mathrm{H}_{8} \mathrm{O}_{3}$, respectively. This can be 
attributed to the presence of sodium nitrate, which reduces the sludge formation on the sides of machined hole thereby giving a better profile of the hole and reducing circularity.

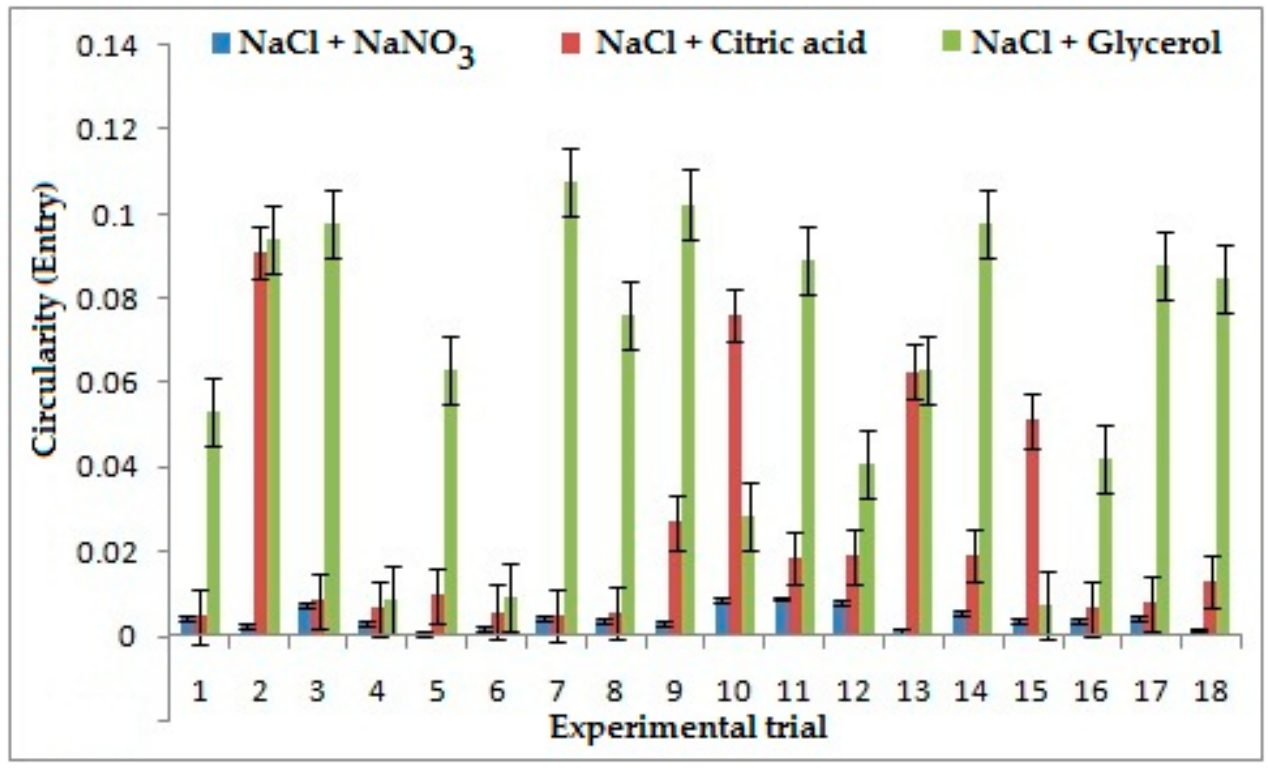

Figure 6. Effects of electrolytes and process parameters on circularity at entry.

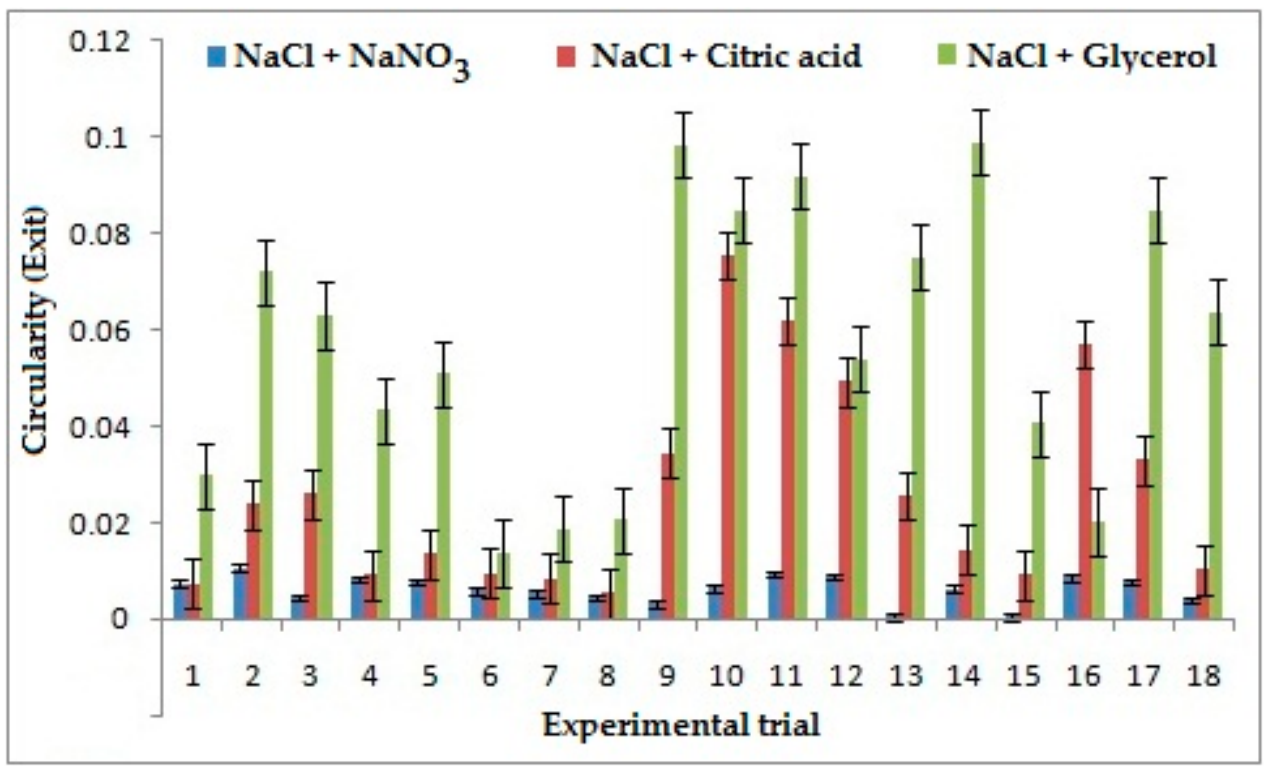

Figure 7. Effects of electrolytes and process parameters on circularity at exit.

\subsection{SEM Analysis of Machined Surface}

The surface profiles of machined workpieces were obtained and analyzed with scanning electron microscope (SEM) images. Figure 8 depicts the surface topography image of machined specimens with $\mathrm{NaCl}+\mathrm{NaNO}_{3}, \mathrm{NaCl}+\mathrm{C}_{3} \mathrm{H}_{8} \mathrm{O}_{3}$ and $\mathrm{NaCl}+\mathrm{C}_{6} \mathrm{H}_{8} \mathrm{O}_{7}$ electrolytes using SEM analysis. The circularity value is mostly due to the size of the crater developed during the electro-chemical micro machining process. The size of the crater is established by the current density and the time duration (pulse-on time + pulse-off time ratio) of applied electrical energy [31]. The $\mathrm{NaCl}+\mathrm{NaNO}_{3}$ has higher electrical conductivity nature to produce a larger peak and valley surface and it has achieved higher circularity $[32,33]$. It has been understood that the higher pulse duration and higher current density can generate a better machined workpiece surface. It has been observed that the 
$\mathrm{NaCl}+\mathrm{C}_{3} \mathrm{H}_{8} \mathrm{O}_{3}$ electrolyte has produced a better micro hole over the workpiece surface due to its decrease of electrical conductivity and reduced quantity of current passing through the electrochemical cell. It has been attained that $\mathrm{NaCl}+\mathrm{C}_{6} \mathrm{H}_{8} \mathrm{O}_{7}$ with higher duty cycle $(66 \%)$ has obtained moderate overcut with tolerable circularity of drilled micro hole over the machined workpiece surface. It has been observed that $\mathrm{NaCl}+\mathrm{C}_{3} \mathrm{H}_{8} \mathrm{O}_{3}$ with lower duty cycle $(33 \%)$ has generated higher overcut due to its thermal and electrical conductivity to create better circularity. The higher pulse-off time has generated lower circularity error because it has higher flushing time to remove the sludge particle from the machining surface to reduce the crater size, which leads to better surface quality.

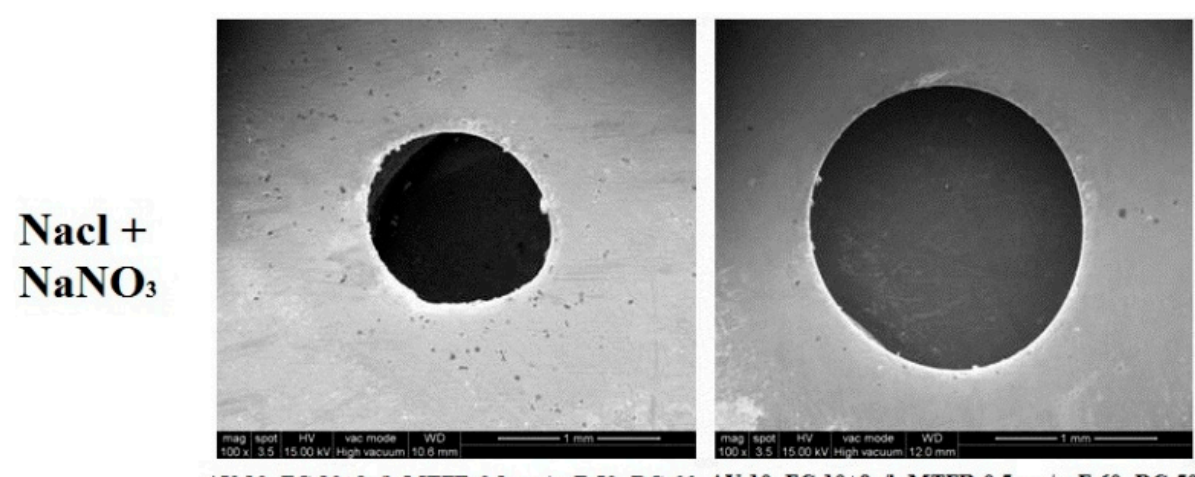

AV-10; EC-10+9g/; MTFR-0.1 $\mu \mathrm{m} / \mathrm{s} ;$ F-50; DC-66 AV-10; EC-10+9g/l; MTFR- $0.5 \mu \mathrm{m} / \mathrm{s} ;$ F-60; DC-50

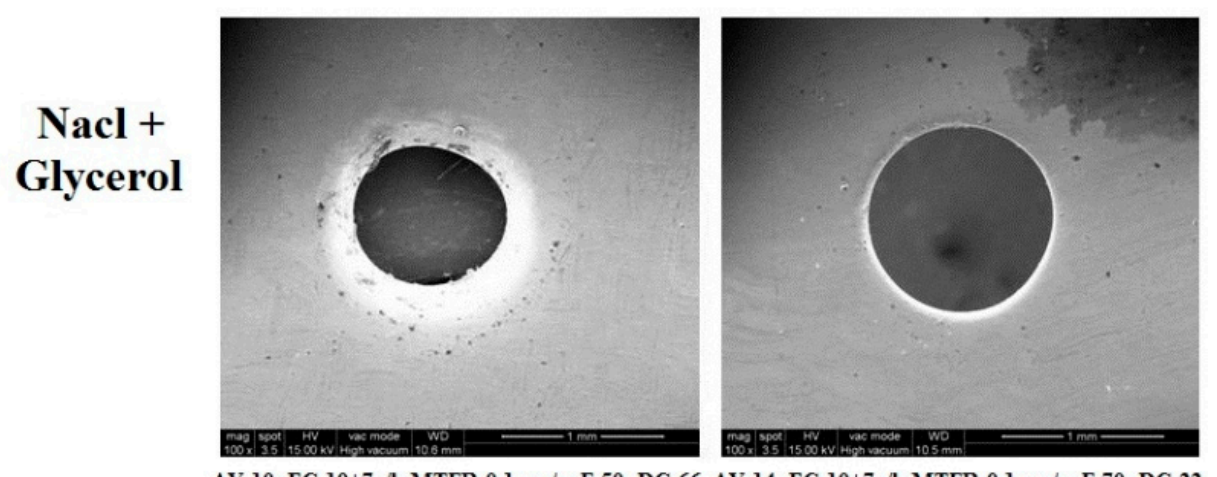

AV-10; EC-10+7g/l; MTFR-0.1 $\mu \mathrm{m} / \mathrm{s} ;$ F-50; DC-66 AV-14; EC-10+7g/l; MTFR-0.1 $\mu \mathrm{m} / \mathrm{s} ;$ F-70; DC-33

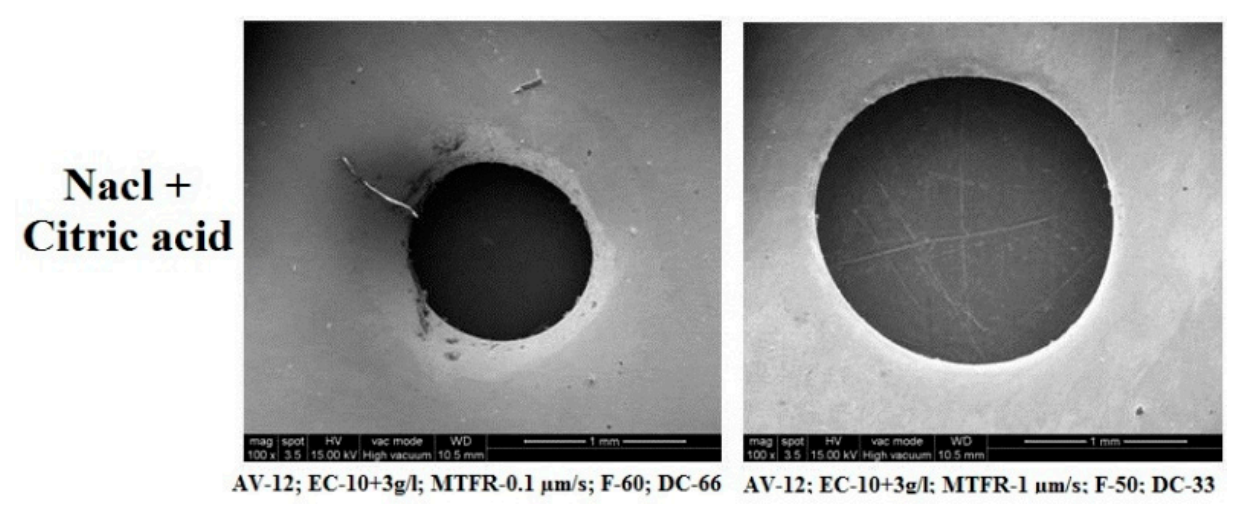

Figure 8. Effects of different electrolyte combinations on circularity using the ECMM process.

\section{Conclusions}

In the present study, an endeavor has been made to find the effects of electrolytes and process parameters involved in the ECMM process on machining Titanium (Ti-6Al$4 \mathrm{~V}$ ) alloy for obtaining better performance measures. From the experimental results, the following conclusions have been drawn. 
- $\mathrm{NaCl}+\mathrm{NaNO}_{3}$ combined electrolyte can provide $56 \%$ and $24 \%$ higher MRR than $\mathrm{NaCl}+\mathrm{Glycerol}$ and $\mathrm{NaCl}+$ Citric acid, respectively, due to the dominance of the Sodium ions present in the electrolyte since it possesses higher reactive nature;

- $\mathrm{NaCl}+\mathrm{Glycerol}$ mixed electrolyte creates $40 \%$ and $22 \%$ lower Overcut than electrolyte combinations $\mathrm{NaCl}+\mathrm{NaNO}_{3}$ and $\mathrm{NaCl}+$ Citric acid, respectively, due to the presence of glycerol, which acts as a good chelating agent by increasing the bonding of ions;

- $\mathrm{NaCl}+$ Citric Acid can improve reduce the conicity by $70 \%$ and $39 \%$ compared to that of $\mathrm{NaCl}+\mathrm{NaNO}_{3}$ and $\mathrm{NaCl}+$ Glycerol due to the presence of citric acid, which reduces the smutting around the machining surface;

- From the SEM analysis, it has been inferred that the $\mathrm{NaCl}+\mathrm{C}_{3} \mathrm{H}_{8} \mathrm{O}_{3}$ electrolyte produces better micro hole over the workpiece surface compared to other electrolytes.

Author Contributions: Conceptualization, M.T. and G.T.; methodology, K.M. and M.T.; software, M.T.; validation, M.T. and G.T.; formal analysis, H.A. and M.T.; investigation, G.T. and S.H.M.; resources, S.H.M.; writing—original draft preparation, M.T. and K.M.; project administration, M.T. and U.U.; funding acquisition, K.M. All authors have read and agreed to the published version of the manuscript.

Funding: This research was financially supported by the Deanship of Scientific Research, King Saud University: Research group No: RG-1440-034.

Acknowledgments: The authors extend their appreciation to the Deanship of Scientific Research at King Saud University for funding this work through research group no. (RG-1440-034).

Conflicts of Interest: The authors declare no conflict of interest.

\section{References}

1. Suresh, H.S.; Sudhir, G.B.; Dayanand, S.B. Analysis of electrochemical machining process parameters affecting material removal rate of hastelloy C-276. Int. J. Adv. Res. Sci. Eng. Technol. 2014, 5, 18-23.

2. Haisch, T.; Mittemeijer, E.; Schultze, J.W. Electrochemical machining of the steel $100 \mathrm{Cr} 6$ in aqueous $\mathrm{NaCl}_{\text {and }} \mathrm{NaNO}_{3}$ solutions: Microstructure of surface films formedby carbides. Electrochim. Acta 2001, 47, 235-241. [CrossRef]

3. Huo, J.; Liu, S.; Wang, Y.; Muthuramalingam, T.; Pi, V.N. A Influence of process factors on surface measures on electrical discharge machined stainless steel using TOPSIS. Mater. Res. Express 2019, 6, 086507. [CrossRef]

4. Rajurkar, K.P.; Sundaram, M.M.; Malshe, A.P. Review of electrochemical and electro discharge machining. Procedia CIRP 2013, 6, 13-26. [CrossRef]

5. Chiou, Y.C.; Lee, R.T.; Chen, T.J.; Chiou, J.M. Fabrication of high aspect ratio micro-rod using a novel electrochemical micromachining method. Precis. Eng. 2012, 36, 193-202. [CrossRef]

6. Mileham, A.R.; Jones, R.M.; Harvey, S.J. Changes of valency state during Electrochemical Machining Production Points. Precis. Eng. 1982, 4, 168-170. [CrossRef]

7. Sen, M.; Shan, H.S. A review of electrochemical macro-to micro-hole drilling processes. Int. J. Mach. Tool. Manuf. 2005, 45, 137-152. [CrossRef]

8. Rajurkar, K.P.; Zhu, D.; Wei, B. Minimization of machining allowance in electrochemical machining. Ann. CIRP 1998, 47, 165-168.

9. Thanigaivelan, R.; Arunachalam, R.M.; Karthikeyan, B.; Loganathan, P. Electrochemical micromachining of stainless steel with acidified sodium nitrate electrolyte. Procedia CIRP 2013, 6, 351-355. [CrossRef]

10. De-Silva, A.K.M.; Altena, H.S.J.; McGeough, J.A. Influence of electrolyte concentration on copying accuracy of precision-ECM. CIRP Ann. Manuf. Technol. 2013, 52, 165-168. [CrossRef]

11. Ayyappan, S.; Sivakumar, K. Experimental investigation on theperformance improvement of electrochemical machining process using oxygen-enriched electrolyte. Int. J. Adv. Manuf. Technol. 2014, 75, 479-487. [CrossRef]

12. Tang, L.; Yang, S. Experimental investigation on the electrochemicalmachining of 00Cr12Ni9Mo4Cu2 material and multi-objective parameters optimization. Int. J. Adv. Manuf. Technol. 2013, 67, 2909-2916. [CrossRef]

13. Kirchner, V.; Cagnon, L.; Schuster, R.; Etrl, G. Electrochemical machining of stainless steel microelements with ultrashort voltage pulses. Appl. Phys. Lett. 2008, 79, 1721-1723. [CrossRef]

14. Huaiqian, B.; Jiawen, X.; Ying, L. Aviation-oriented Micromachining Technology Micro-ECM in pure Water. Chin. J. Aeronaut. 2008, 218, 455-461. [CrossRef]

15. Shibuya, N.; Ito, Y.; Natsu, W. Electrochemical Machining of Tungsten Carbide Alloy Micro-pin with $\mathrm{NaNO}_{3}$ Solution. Int. J. Precis. Eng. Manuf. 2012, 13, 2075-2078. [CrossRef]

16. Spieser, A.; Ivanov, A. Recent developments and research challenges in electrochemical micromachining ( $\mu$ ECM). Int. J. Adv. Manuf. Technol. 2013, 69, 563-581. [CrossRef] 
17. Rajurkar, K.P.; Zhu, D.; McGeough, J.A.; Kozak, J.; Silva, A.D. New developments in electro-chemical machining. Ann. CIRP 1999, 48, 567-579. [CrossRef]

18. Kozak, J.; Rajurkar, K.P.; Makkar, Y. Study of pulse electrochemical micromachining. J. Manuf. Proc. 2004, 6, 7-14. [CrossRef]

19. Geethapriyan, T.; Kalaichelvan, K.; Muthuramalingam, T. Influence of coated tool electrode on drilling Inconel alloy 718 in Electrochemical micro machining. Procedia CIRP 2016, 46, 127-130. [CrossRef]

20. Ginestra, P.; Ferraro, R.M.; Hauber, K.Z.; Abeni, A.; Giliani, S.; Ceretti, E. Selective Laser Melting and Electron Beam Melting of Ti6Al4V for Orthopedic Applications: A Comparative Study on the Applied Building Direction. Materials 2020, 13, 5584. [CrossRef]

21. Lowther, M.; Louth, S.; Davey, A.; Hussain, A.; Ginestra, P.; Carter, L.; Eisenstein, N.; Grover, L.; Cox, S. Clinical, industrial, and research perspectives on powder bed fusion additively manufactured metal implants. Addit. Manuf. 2019, 28, 565-584. [CrossRef]

22. Davydov, A.D.; Kabanova, T.B.; Volgin, V.M. Electrochemical Machining of Titanium. Review. Russ. J. Electrochem. 2017, 53, 941-965. [CrossRef]

23. Geethapriyan, T.; Muthuramalingam, T.; Kalaichelvan, K. Influence of Process Parameters on Machinability of Inconel 718 by Electrochemical Micromachining Process using TOPSIS Technique. Arab. J. Sci. Eng. 2019, 44, 7945-7955. [CrossRef]

24. Muthuramalingam, T.; Ramamurthy, A.; Moiduddin, K.; Alkindi, M.; Ramalingam, S.; Alghamdi, O. Enhancing the Surface Quality of Micro Titanium Alloy Specimen in WEDM Process by Adopting TGRA-Based Optimization. Materials 2020, 13, 1440.

25. Senthilkumar, C.; Ganesan, G.; Karthikeyan, R. Study of electrochemical machining characteristics of Al/SiCp composites. Int. J. Adv. Manuf. Technol. 2009, 43, 256-263. [CrossRef]

26. Geethapriyan, T.; Muthuramalingam, T.; Vasanth, S.; Thavamani, J.; Srinivasan, V.H. Influence of Nanoparticles-Suspended Electrolyte on Machinability of Stainless Steel 430 Using Electrochemical Micro-machining Process. Lect. Notes Mech. Eng. Adv. Manuf. Process. 2018, 433-440. [CrossRef]

27. Mingcheng, G.; Yongbin, Z.; Lingchao, M. Electrochemical Micromachining of Square Holes in StainlessSteel in $\mathrm{H}_{2} \mathrm{SO}_{4}$. Int. J. Electrochem. Sci. 2019, 14, 414-426.

28. Saxena, K.K.; Qian, J.; Reynaerts, D. A review on process capabilities of electrochemical micromachining and itshybrid variants. Int. J. Mach. Tool. Manuf. 2018, 127, 28-56. [CrossRef]

29. Thakur, A.; Tak, M.; Mote, R.G. Electrochemical micromachining behavior on 17-4 PH stainless steel using different electrolytes. Procedia Manuf. 2019, 34, 355-361. [CrossRef]

30. Leese, R.J.; Ivanov, A. Electrochemical micromachining: Anintroduction. Adv. Mech. Eng. 2016, 8, 1-13. [CrossRef]

31. Geethapriyan, T.; Kalaichelvan, K.; Muthuramalingam, T.; Rajadurai, A. Performance Analysis of Process Parameters on Machining $\alpha-\beta$ Titanium Alloy in Electrochemical Micromachining Process. Proc. Inst. Mech. Eng. Part B J. Eng. Manuf. 2018, 232, 1577-1589. [CrossRef]

32. Tang, L.; Li, B.; Yang, S.; Duan, Q.; Kang, B. The effect of electrolyte current density on the electrochemical machining S-03 material. Int. J. Adv. Manuf. Technol. 2014, 71, 1825-1833. [CrossRef]

33. Chun, K.H.; Kim, S.H.; Lee, E.S. Analysis of the relationship between electrolyte characteristics and electrochemical machinability in PECM on invar (Fe-Ni) fine sheet. Int. J. Adv. Manuf. Technol. 2016, 87, 3009-3017. [CrossRef] 